K. A. McAuley • C. M. Hopkins · K. J. Smith •

R. T. McLay - S. M. Williams - R. W. Taylor •

J. I. Mann

\title{
Comparison of high-fat and high-protein diets with a high-carbohydrate diet in insulin-resistant obese women
}

Received: 4 May 2004 / Accepted: 10 October 2004 / Published online: 23 December 2004

C) Springer-Verlag 2004

\begin{abstract}
Aims/hypothesis: A diet low in saturated fatty acids and rich in wholegrains, vegetables and fruit is recommended in order to reduce the risk of obesity, cardiovascular disease and type 2 diabetes mellitus. However there is widespread interest in high-fat ("Atkins Diet") and high-protein ("Zone Diet") alternatives to the conventional high-carbohydrate, high-fibre approach. We report on a randomised trial that compared these two alternative approaches with a conventional diet in overweight insulin-resistant women. Methods: Ninety-six normoglycaemic, insulin-resistant women (BMI $>27 \mathrm{~kg} / \mathrm{m}^{2}$ ) were randomised to one of three dietary interventions: a highcarbohydrate, high-fibre (HC) diet, the high-fat (HF) Atkins Diet, or the high-protein (HP) Zone Diet. The experimental approach was designed to mimic what might be achieved in clinical practice: the recommendations involved advice concerning food choices and were not prescriptive in terms of total energy. There were supervised weight loss and weight maintenance phases ( 8 weeks each), but there was no contact between the research team and the participants during the final 8 weeks of the study. Outcome was assessed in terms of body composition and indicators of cardiovascular and diabetes risk. Results: Body weight, waist circumference, triglycerides and insulin levels decreased with all three diets but, apart from insulin, the reductions were significantly greater in
\end{abstract}

K. A. McAuley $(\bowtie) \cdot$ J. I. Mann

Edgar National Centre for Diabetes Research, Medical and

Surgical Sciences, University of Otago,

PO Box 56 Dunedin, New Zealand

e-mail: kirsten.mcauley@stonebow.otago.ac.nz

Tel.: +64-3-4798153

Fax: +64-3-4747641

K. A. McAuley · C. M. Hopkins · K. J. Smith · R. T. McLay R. W. Taylor · J. I. Mann

Department of Human Nutrition, University of Otago,

Dunedin, New Zealand

S. M. Williams

Department of Preventive and Social Medicine, University of Otago,

Dunedin, New Zealand the HF and HP groups than in the HC group. These observations suggest that the popular diets reduced insulin resistance to a greater extent than the standard dietary advice did. When compared with the $\mathrm{HC}$ diet, the $\mathrm{HF}$ and HP diets were shown to produce significantly $(p<0.01)$ greater reductions in several parameters, including weight loss ( $\mathrm{HF}-2.8 \mathrm{~kg}, \mathrm{HF}-2.7 \mathrm{~kg}$ ), waist circumference (HF $-3.5 \mathrm{~cm}, \mathrm{HF}-2.7 \mathrm{~cm}$ ) and triglycerides $(\mathrm{HF}-0.30 \mathrm{mmol} / 1$, HF $-0.22 \mathrm{mmol} / \mathrm{l}$ ). LDL cholesterol decreased in individuals on the HC and HP diets, but tended to fluctuate in those on the HF diet to the extent that overall levels were significantly lower in the HP group than in the HF group $(-0.28 \mathrm{mmol} / 1,95 \%$ CI $0.04-0.52, p=0.02)$. Of those on the HF diet, $25 \%$ showed a $>10 \%$ increase in LDL cholesterol, whereas this occurred in only $13 \%$ of subjects on the $\mathrm{HC}$ diet and 3\% of those on the HP diet. Conclusions/ interpretation: In routine practice a reduced-carbohydrate, higher protein diet may be the most appropriate overall approach to reducing the risk of cardiovascular disease and type 2 diabetes. To achieve similar benefits on a $\mathrm{HC}$ diet, it may be necessary to increase fibre-rich wholegrains, legumes, vegetables and fruits, and to reduce saturated fatty acids to a greater extent than appears to be achieved by implementing current guidelines. The HF approach appears successful for weight loss in the short term, but lipid levels should be monitored. The potential deleterious effects of the diet in the long term remain a concern.

Keywords Cardiovascular disease $\cdot$ High-carbohydrate diet · High-fat diet · High-protein diet · Insulin resistance . Obese - Type 2 diabetes $\cdot$ Weight loss

Abbreviations CRP: C-reactive protein - HC: high carbohydrate $\cdot$ HF: high fat $\cdot$ HP: high protein

\section{Introduction}

Lifestyle modification offers the only proven hope of stemming the tide of the global epidemic of type 2 
diabetes. Two randomised controlled trials carried out in Finland and the United States have demonstrated substantial reductions in the risk of progression of IGT to type 2 diabetes $[1,2]$. In both studies the recommended diets were low in saturated fatty acids, and rich in wholegrains, vegetables and fruit, such that fibre-rich carbohydrate provided about $50 \%$ of the total daily energy intake, saturated fatty acids less than $10 \%$, monounsaturated and polyunsaturated fatty acids about $20 \%$, and protein the remainder. A similar diet has been shown to be associated with improved insulin sensitivity in normoglycaemic insulin-resistant individuals [3].

In each of the trials, dietary recommendations were combined with advice to increase physical activity, and the improvements in insulin action and measures of glycaemia occurred in parallel with weight reduction. The macronutrient composition and recommended food choices of these experimental diets are virtually identical to the recommendations set out by various national and international bodies for the treatment of established diabetes $[4,5]$ and the reduction of cardiovascular risk in people with diabetes and in the population as a whole [6].

Despite the consistency amongst official recommendations there has been widespread interest in alternative dietary approaches aimed at weight loss and the reduction of cardiovascular and diabetes risk. The most widely adopted are the Atkins Diet [7], a very low carbohydrate diet and the Zone Diet [8], a high-protein approach. Neither diet involves prescription of energy intake. While both diets clearly have the potential to help reduce excess adiposity, it is unclear as to whether weight loss can be sustained, whether there are adverse metabolic consequences, and whether the diets are suitable for long-term use in terms of palatability. High rates of loss to follow-up and consequent inability to analyse results according to intention to treat, restrict the number of clinically useful conclusions that can be drawn from the limited number of published trials [9-11]. To date, only one study has simultaneously compared both the Atkins Diet and the Zone Diet with a conventional high-carbohydrate, highfibre diet [11], and the results of this were inconclusive due to the very high attrition rate. We report here the results of a randomised trial that compared the two alternative approaches with a conventional diet in a group of women considered to be at high risk of developing type 2 diabetes due to being overweight and insulin resistant.

\section{Subjects and methods}

Eligibility Five hundred women responded to local advertisements regarding this study, which was approved by the Otago Ethics Committee. A telephone interview identified overweight women aged 30-70 years who were not pregnant or planning pregnancy, did not have a major medical condition, and were not currently undertaking a formal weight loss programme or following a strict vegetarian diet. A 75-g OGTT was performed for 251 of the 314 potentially eligible individuals who were found to have a BMI $>27 \mathrm{~kg} / \mathrm{m}^{2}$ during a screening visit at which written consent was obtained, demographic details and medical history were recorded, and a blood sample drawn for fasting glucose, insulin, lipid profile, serum creatinine and liver function tests. Ninety-six participants of European descent were eligible for randomisation to one of three groups by virtue of normal glucose tolerance [12], total cholesterol $<7 \quad \mathrm{mmol} / \mathrm{l}$, creatinine $<130 \mu \mathrm{mol} / \mathrm{l}$, normal liver function tests and reduced predicted insulin sensitivity (insulin sensitivity score $\leq 6.3 \mathrm{G} \mathrm{mIU}^{-1} \mathrm{l}^{-1}$ ) [13].

Study design Although ad libitum consumption was advised regardless of group allocation, the first 8 weeks of the study were intended to be a weight loss phase, with dietary advice reinforced during weekly reviews. Similar supervision continued during the weight maintenance phase (weeks 8 to 16). From week 16 to week 24, participants were asked to continue to follow their dietary programme, but there was no contact with the research team. None of the diets were formally energy restricted during any phase. As regards exercise, all three groups were advised to participate in 30 min of any activity on 5 days/week.

High-fat diet (Atkins Diet) This dietary programme was based on the guidelines described in by Atkins [7]. There were no specific macronutrient targets except for carbohydrates. During the first 2 weeks of the 8 -week weight loss phase of the intervention, participants were instructed to limit certain foods in order to consume less than $20 \mathrm{~g}$ of carbohydrate daily. Participants were provided with tables indicating acceptable foods, separating restricted and free foods, and foods which had to be excluded. During weeks 3 to 8 of the weight loss phase, carbohydrate was reintroduced by the addition of $5 \mathrm{~g} /$ day each week, so that a maximum of $50 \mathrm{~g}$ of carbohydrate per day was consumed by week 8 . During weeks 8 to 16 (the supervised weight maintenance phase of the intervention) the principle of increasing carbohydrate intake from the specific food lists by $5 \mathrm{~g} /$ day each week was continued until each participant found the maximum level of carbohydrate consumption without weight gain. During the unsupervised follow-up phase of the intervention, participants were encouraged to consume the amount of carbohydrate that would help to avoid weight gain.

High-protein diet (Zone Diet) The Zone Diet recommends that of the total energy provided by each meal and snack, $40 \%$ should be from low glycaemic index carbohydrate, $30 \%$ from protein and 30\% from fat (predominantly monounsaturated) [8]. Participants were advised to eat five times daily, with no more than $5 \mathrm{~h}$ between meals. The programme was presented to participants as a series of tables listing food types and serving sizes. Participants were advised to consume an appreciable amount of food from the protein table, to fill up with foods from the fruit and vegetable table, and to consume small amounts of items from the fats and oils table. A further table listed 
food items to be restricted to one serving per day. During the supervised weight maintenance phase, subjects were instructed to consume slightly larger portions of foods in the evening to maintain their body weight. During the unsupervised follow-up phase, participants were encouraged to continue consuming appropriate foods in quantities that facilitated weight maintenance.

High-carbohydrate, high-fibre diet (control group) The nutrient composition of this diet was based on that recommended by Diabetes and Nutrition Study Group (DNSG) of the European Association for the Study of Diabetes (EASD) [5], and the diet was implemented using the national healthy eating guidelines, with slight modifications [14]. These guidelines focus on the consumption of specific food groups in specified daily amounts and consist of the following: (1) at least six servings of breads and cereals (preferably wholegrains); (2) at least three servings of vegetables and two of fruit, with emphasis on those rich in soluble fibre; (3) at least two servings of lowfat milk or milk products; and (4) at least one serving of lean meat, chicken, seafood, eggs, cooked dried beans, peas or lentils (with legumes rich in soluble fibre especially encouraged). Advice to reduce dietary fat, salt and sugar intakes was also given. Each guideline was followed by a table containing serving sizes, healthy choices for that food group, and foods to be restricted as much as possible. During the supervised weight maintenance phase of the intervention, participants were instructed to consume slightly larger portions for their evening meal to maintain body weight. Similar advice was given for the unsupervised follow-up phase.

Outcome measurements Height, weight and waist circumference (at the midpoint between the anterior superior iliac crest and the lowest rib) were measured, and BMI was calculated. Blood pressure was recorded after $5 \mathrm{~min}$ of rest using random-zero sphygmomanometers, and a 75-g OGTT was performed, with fasting and 2-h measurements of glucose and insulin assessed [13]. Fasting samples were also obtained for lipid measurements [13] and for assessment of high-sensitivity C-reactive protein (CRP) using a kit from Roche Diagnostics (Indianapolis, IN, USA) which had an intra-assay CV of $1.5 \%$. A measure of body fat was obtained using an IMP5 Bioimpedance Analyser (Impedimed, Eight Mile Plains, QLD, Australia), with subjects in a fasted state after emptying their bladders and having refrained from alcohol and exercise for the previous $24 \mathrm{~h}$ [15]. Participants were given scales to weigh food and asked to complete a 3-day dietary record. All measurements were made at baseline and during the final week of each of the three experimental periods.

Statistical analysis A difference in weight loss of $3 \mathrm{~kg}$ between the $\mathrm{HC}$ diet and either of the other two diets was considered to be of clinical importance. An earlier study [3] indicated that the root mean square error (an estimate of SD) for weight loss, adjusted for baseline values, was $4.5 \mathrm{~kg}$. This is equivalent to an effect size of 0.66 or 0.70 .
Two samples of 32 subjects have the potential to detect this difference with $80 \%$ power using the $5 \%$ level of significance. A random allocation sequence was generated in blocks of nine. Sequentially numbered envelopes were used to assign participants to each group. There was no stratification. It was not possible to blind researchers or participants; however, the groups were designated by codes rather than actual names to minimise crosscontamination between the groups. The data were analysed according to intention to treat.

Mixed models were used to analyse the data. The models included a random effect for each person and assumed an underlying variance-covariance structure because of the multiple measures for each person. These provided appropriate standard errors for the statistical tests. Baseline measures were included to adjust for any baseline imbalance. The models examine relative change by setting the groups equal on the first occasion, and are the recommended way of overcoming problems associated with regression to the mean [16]. Although the tests between the two alternative diets and the conventional diet were planned a priori, an overall test for all three diets was also carried out to compare the alternative diets. The value of the test statistic was compared with chi square distribution with appropriate degrees of freedom. The results are not reported in detail if the overall test was not statistically significant. Values obtained for fasting insulin, CRP and liver enzymes were logarithmically transformed to stabilise the variance. The overall differences (with $95 \%$ confidence intervals) between each pair of diets, based on measurements taken at weeks 8,16 and 24 , are presented for each outcome. Interaction effects between diet and time were examined. The results are presented graphically as adjusted means. The data were analysed using the xtreg procedure in the STATA Statistical Software Package, Release 8.0 (STATA, College Station, TX, USA). A $p$ value of less than 0.05 was regarded as statistically significant.

\section{Results}

Of the 96 eligible participants, 12 withdrew from the study (Fig. 1). Three withdrew after baseline measurements had been made, before the start of the dietary intervention, and were not included in the analysis.

All three groups had diets of similar macronutrient composition at baseline (Table 1). The reported energy intake did not differ between the three groups at any stage of the 6-month study. The high-fat (HF) group met the week 8 carbohydrate target. Those on the high-protein (HP) diet did not meet the target protein and carbohydrate levels, as more energy was derived from total fat than intended. Those on the high-carbohydrate, high-fibre (HC) diet met the targets for total fat, but did not meet the targets for saturated fat, carbohydrates or fibre. Table 2 shows the differences between the three diets in terms of their macronutrient content. Compared with the $\mathrm{HC}$ diet, the HF diet was much lower in carbohydrate ( $-94 \mathrm{~g}, 95 \%$ 
Fig. 1 Trial profile. Asterisk Subjects who withdrew from the study were followed for outcome measures

Table 1 Nutrient composition of the different diets

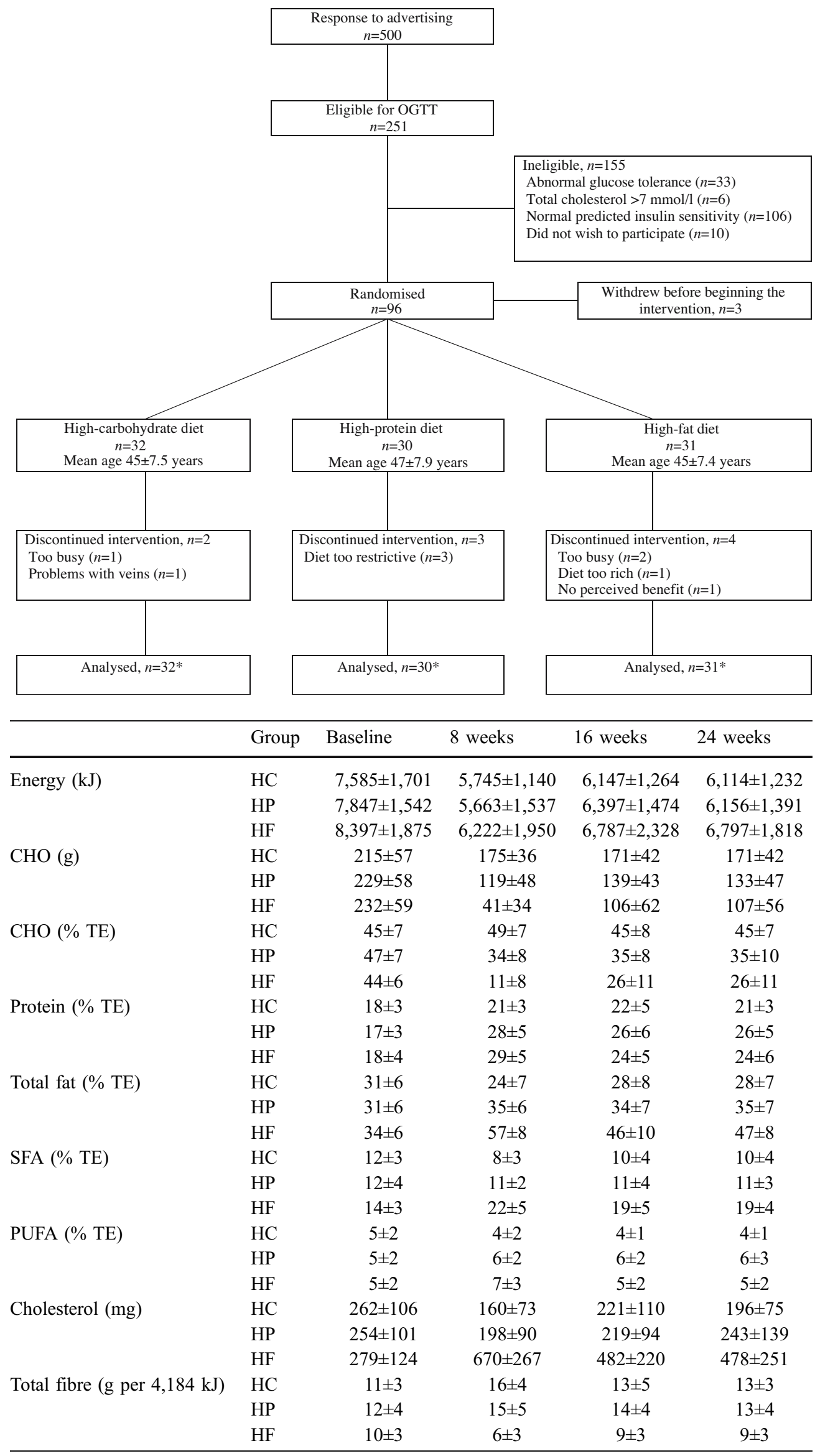

Data are means $\pm \mathrm{SD}$. At baseline $\mathrm{HC} n=32$, HP $n=30$, HF $n=31$; at 8 weeks HC $n=31$, HP $n=29$, HF $n=28$; at 16 weeks HC $n=29$, HP $n=28$, HF $n=30$; at 24 weeks $\mathrm{HC} n=29, \mathrm{HP}=29$,

$\mathrm{HF}=28$

The dietary targets were as follows: $\mathrm{HC}$ diet: $\mathrm{CHO}>55 \%$ TE, total fat $<30 \%$ TE, saturated fat $<8 \% \mathrm{TE}$, protein $=15 \% \mathrm{TE}$, fibre $>25-30 \mathrm{~g}$ /day; HP diet: $\mathrm{CHO}=40 \% \mathrm{TE}$, total fat $=30 \%$ TE, protein $=30 \%$ TE; HF diet: $\mathrm{CHO}<20 \mathrm{~g} /$ day for the first 2 weeks, increasing up to $50 \mathrm{~g}$ /day by 8 weeks CHO carbohydrate, $P U F A$ polyunsaturated fatty acids, $S F A$ saturated fatty acids, $T E$ total energy 
Table 2 Differences between the nutrient content of the diets adjusted for baseline values

\begin{tabular}{|c|c|c|c|c|}
\hline & Diet group & Mean difference between diets & $95 \% \mathrm{CI}$ & $p$ value \\
\hline \multirow[t]{3}{*}{ Energy $(\mathrm{kJ})$} & HP-HC & -107 & -734 to 519 & 0.74 \\
\hline & $\mathrm{HF}-\mathrm{HC}$ & 249 & -387 to 886 & 0.44 \\
\hline & HF-HP & 357 & -276 to 990 & 0.27 \\
\hline \multirow[t]{3}{*}{$\mathrm{CHO}(\mathrm{g})$} & HP-HC & -47 & -65 to -29 & 0.000 \\
\hline & HF-HC & -94 & -112 to -75 & 0.000 \\
\hline & HF-HP & -46 & -65 to -28 & 0.000 \\
\hline \multirow[t]{3}{*}{ CHO (\% TE) } & HP-HC & -12 & -16 to -8 & 0.000 \\
\hline & HF-HC & -25 & -29 to -21 & 0.000 \\
\hline & HF-HP & -13 & -17 to -9 & 0.000 \\
\hline \multirow[t]{3}{*}{ Protein (g) } & HP-HC & 20 & 11 to 30 & 0.000 \\
\hline & $\mathrm{HF}-\mathrm{HC}$ & 19 & 9 to 29 & 0.000 \\
\hline & HF-HP & -2 & -11 to 8 & 0.76 \\
\hline \multirow[t]{3}{*}{ Protein $(\%$ TE) } & HP-HC & 6 & 4 to 8 & 0.000 \\
\hline & HF-HC & 4 & 3 to 6 & 0.000 \\
\hline & HF-HP & -1 & -3 to 0 & 0.10 \\
\hline \multirow[t]{3}{*}{ Total fat $(\mathrm{g})$} & HP-HC & 11 & 0 to 23 & 0.056 \\
\hline & $\mathrm{HF}-\mathrm{HC}$ & 40 & 29 to 52 & 0.000 \\
\hline & HF-HP & 29 & 17 to 41 & 0.000 \\
\hline \multirow[t]{3}{*}{ Total fat (\% TE) } & HP-HC & 8 & 5 to 11 & 0.000 \\
\hline & HF-HC & 22 & 19 to 26 & 0.000 \\
\hline & HF-HP & 14 & 11 to 18 & 0.000 \\
\hline \multirow[t]{3}{*}{ SFA (\% TE) } & HP-HC & 2 & 0 to 3 & 0.029 \\
\hline & HF-HC & 10 & 8 to 11 & 0.000 \\
\hline & HF-HP & 8 & 7 to 10 & 0.000 \\
\hline \multirow[t]{3}{*}{ MUFA (\% TE) } & HP-HC & 4 & 3 to 6 & 0.000 \\
\hline & HF-HC & 9 & 7 to 10 & 0.000 \\
\hline & HF-HP & 4 & 3 to 6 & 0.000 \\
\hline \multirow[t]{3}{*}{ PUFA (\% TE) } & HP-HC & 1 & 1 to 2 & 0.000 \\
\hline & HF-HC & 1 & 1 to 2 & 0.001 \\
\hline & HF-HP & 0 & -1 to 1 & 0.70 \\
\hline \multirow[t]{3}{*}{ Cholesterol (mg) } & HP-HC & 26 & -37 to 89 & 0.42 \\
\hline & HF-HC & 345 & 282 to 408 & 0.000 \\
\hline & HF-HP & 319 & 255 to 382 & 0.000 \\
\hline \multirow[t]{3}{*}{ Total sugars (g) } & HP-HC & -2 & -13 to 9 & 0.73 \\
\hline & HF-HC & -44 & -55 to -33 & 0.000 \\
\hline & HF-HP & -42 & -53 to -32 & 0.000 \\
\hline \multirow[t]{3}{*}{ Total fibre (g per $4,184 \mathrm{~kJ})$} & HP-HC & -0.8 & -2.2 to 0.6 & 0.26 \\
\hline & HF-HC & -5.6 & -6.9 to -4.2 & 0.000 \\
\hline & HF-HP & -4.8 & -6.2 to -3.4 & 0.000 \\
\hline
\end{tabular}

The values shown are the combined results for weeks 8,16 and 24. At baseline HC $n=32$, HP $n=30$, HF $n=31$; at 8 weeks HC $n=31$, HP $n=29$, HF $n=28$; at 16 weeks $\mathrm{HC} n=29$, HP $n=28$ $\mathrm{HF} n=30$; at 24 weeks $\mathrm{HC} n=29$, $\mathrm{HP}=29, \mathrm{HF}=28$

CHO carbohydrate, MUFA monounsaturated fatty acids, $P U F A$ polyunsaturated fatty acids, $S F A$ saturated fatty acids, $T E$ total energy loss and reductions in BMI, waist circumference and fat mass that were maintained throughout the study (Fig. 2). Fasting triglycerides and insulin also decreased appreciably with all three diets. Systolic and diastolic blood pressures were modestly reduced. Blood glucose levels $(0$ and $2 \mathrm{~h}$ ), creatinine, liver enzymes, CRP and the albumin/ creatinine ratio did not change throughout the observation period. Table 4 shows the differences in the measured parameters between the three diets after adjusting for baseline differences. Compared with the control (HC) group, those on the HF and the HP diets lost a significantly greater amount of weight. Similar between-group differences were observed for waist circumference and fat mass. Diastolic blood pressure was significantly lower in the HF group than in the $\mathrm{HC}$ group $(-3 \mathrm{~mm} \mathrm{Hg}, 95 \% \mathrm{CI}-6$ to 0 , point. All three groups achieved an appreciable weight 
Table 3 Characteristics of the different diet groups

\begin{tabular}{|c|c|c|c|c|c|c|c|c|c|}
\hline Variable & Diet & Samples & Baseline & Samples & 8 weeks & Samples & 16 weeks & Samples & 24 weeks \\
\hline Weight (kg) & HP & 30 & $93.2 \pm 14.5$ & 30 & $87.8 \pm 13.7$ & 28 & $86.2 \pm 14.6$ & 29 & $86.3 \pm 14.2$ \\
\hline \multirow[t]{2}{*}{ BMI $\left(\mathrm{kg} / \mathrm{m}^{2}\right)$} & $\mathrm{HC}$ & 32 & $36.6 \pm 5.6$ & 31 & $35.2 \pm 5.6$ & 31 & $35.0 \pm 5.5$ & 30 & $34.9 \pm 5.6$ \\
\hline & HP & 30 & $34.5 \pm 5.3$ & 30 & $32.4 \pm 4.8$ & 28 & $32.0 \pm 5.0$ & 29 & $31.5 \pm 5.1$ \\
\hline \multirow{2}{*}{ Waist circumference $(\mathrm{cm})$} & $\mathrm{HP}$ & 30 & $108.0 \pm 11.5$ & 30 & $100.3 \pm 9.6$ & 28 & $100.3 \pm 9.9$ & 29 & $99.2 \pm 10.9$ \\
\hline & $\mathrm{HF}$ & 31 & $108.9 \pm 9.9$ & 31 & $100.6 \pm 9.6$ & 30 & $99.8 \pm 10.0$ & 28 & $99.1 \pm 9.2$ \\
\hline \multirow[t]{3}{*}{ Fat-free mass (kg) } & $\mathrm{HC}$ & 30 & $52.8 \pm 6.1$ & 30 & $51.0 \pm 6.3$ & 29 & $50.9 \pm 6.3$ & 27 & $50.7 \pm 6.6$ \\
\hline & HP & 28 & $50.3 \pm 6.5$ & 30 & $48.7 \pm 6.6$ & 28 & $48.0 \pm 6.8$ & 28 & $47.5 \pm 6.8$ \\
\hline & $\mathrm{HF}$ & 28 & $51.4 \pm 5.5$ & 30 & $49.4 \pm 5.3$ & 30 & $49.3 \pm 5.0$ & 27 & $48.9 \pm 5.4$ \\
\hline \multirow{2}{*}{ Systolic BP (mmHg) } & HP & 29 & $124 \pm 13$ & 29 & $122 \pm 14$ & 27 & $122 \pm 10$ & 28 & $121 \pm 10$ \\
\hline & $\mathrm{HF}$ & 31 & $130 \pm 14$ & 30 & $118 \pm 14$ & 30 & $123 \pm 13$ & 28 & $126 \pm 14$ \\
\hline \multirow[t]{3}{*}{ Diastolic BP (mmHg) } & $\mathrm{HC}$ & 31 & $81 \pm 10$ & 30 & $80 \pm 9$ & 29 & $81 \pm 10$ & 29 & $82 \pm 10$ \\
\hline & HP & 29 & $80 \pm 9$ & 29 & $76 \pm 7$ & 27 & $79 \pm 7$ & 28 & $79 \pm 7$ \\
\hline & $\mathrm{HF}$ & 31 & $83 \pm 10$ & 30 & $76 \pm 10$ & 30 & $79 \pm 9$ & 28 & $81 \pm 8$ \\
\hline \multirow{3}{*}{$\begin{array}{l}\text { Total cholesterol } \\
(\mathrm{mmol} / \mathrm{l})\end{array}$} & $\mathrm{HC}$ & 32 & $5.9 \pm 0.9$ & 31 & $5.3 \pm 0.9$ & 31 & $5.4 \pm 0.9$ & 30 & $5.3 \pm 1.0$ \\
\hline & HP & 30 & $5.7 \pm 1.0$ & 30 & $5.0 \pm 0.8$ & 28 & $5.2 \pm 0.8$ & 28 & $5.2 \pm 0.9$ \\
\hline & $\mathrm{HF}$ & 31 & $5.8 \pm 1.0$ & 31 & $5.5 \pm 1.2$ & 30 & $5.4 \pm 1.0$ & 28 & $5.5 \pm 1.1$ \\
\hline \multirow[t]{2}{*}{ LDL cholesterol (mmol/l) } & $\mathrm{HC}$ & 32 & $3.9 \pm 0.8$ & 31 & $3.6 \pm 0.9$ & 31 & $3.7 \pm 0.9$ & 30 & $3.5 \pm 0.9$ \\
\hline & $\mathrm{HP}$ & 30 & $3.7 \pm 0.8$ & 30 & $3.3 \pm 0.7$ & 28 & $3.4 \pm 0.8$ & 28 & $3.4 \pm 0.8$ \\
\hline \multirow[t]{3}{*}{ Fasting glucose $(\mathrm{mmol} / \mathrm{l})$} & $\mathrm{HC}$ & 32 & $5.0 \pm 0.6$ & 31 & $4.8 \pm 0.4$ & 31 & $4.8 \pm 0.5$ & 30 & $4.7 \pm 0.4$ \\
\hline & HP & 30 & $5.1 \pm 0.5$ & 30 & $5.0 \pm 0.6$ & 28 & $5.0 \pm 0.5$ & 28 & $4.9 \pm 0.4$ \\
\hline & $\mathrm{HF}$ & 31 & $5.1 \pm 0.6$ & 31 & $4.8 \pm 0.4$ & 30 & $4.8 \pm 0.40$ & 28 & $4.8 \pm 0.6$ \\
\hline \multirow[t]{3}{*}{ 2-h Glucose (mmol/l) } & $\mathrm{HC}$ & 32 & $5.5 \pm 1.2$ & 31 & $5.4 \pm 1.4$ & 30 & $5.7 \pm 1.5$ & 27 & $5.3 \pm 1.3$ \\
\hline & HP & 30 & $5.7 \pm 1.2$ & 30 & $5.8 \pm 1.2$ & 28 & $6.0 \pm 1.4$ & 28 & $5.5 \pm 0.9$ \\
\hline & $\mathrm{HF}$ & 31 & $5.9 \pm 1.3$ & 31 & $6.4 \pm 1.7$ & 30 & $5.7 \pm 1.3$ & 28 & $5.1 \pm 1.2$ \\
\hline \multirow[t]{3}{*}{ Fasting insulin (mIU/l) } & $\mathrm{HC}$ & 32 & $\begin{array}{c}14.8 \\
(12.2-17.8)\end{array}$ & 31 & $9.2(7.6-11.1)$ & 31 & $8.5(6.8-10.6)$ & 30 & $10.6(8.8-12.8)$ \\
\hline & $\mathrm{HP}$ & 30 & $\begin{array}{c}11.9 \\
(10.2-13.8)\end{array}$ & 30 & $6.7(5.7-7.8)$ & 28 & $8.1(6.7-9.8)$ & 28 & $9.0(7.8-10.3)$ \\
\hline & $\mathrm{HF}$ & 31 & $\begin{array}{c}15.0 \\
(12.2-18.4)\end{array}$ & 31 & $8.7(7.4-10.2)$ & 30 & $9.0(7.3-11.1)$ & 28 & $9.1(7.7-10.9)$ \\
\hline \multirow[t]{3}{*}{ CRP (mg/l) } & $\mathrm{HC}$ & 32 & $\begin{array}{c}3.56 \\
(3.25-3.91)\end{array}$ & 31 & $\begin{array}{c}3.56 \\
(2.43-5.23)\end{array}$ & 31 & $\begin{array}{c}3.27 \\
(2.23-4.79)\end{array}$ & 30 & $\begin{array}{c}3.10 \\
(2.22-4.32)\end{array}$ \\
\hline & HP & 30 & $\begin{array}{c}3.65 \\
(3.30-4.04)\end{array}$ & 30 & $\begin{array}{c}3.38 \\
(2.50-4.55)\end{array}$ & 28 & $\begin{array}{c}3.05 \\
(2.23-4.17)\end{array}$ & 28 & $\begin{array}{c}3.11 \\
(2.23-4.34)\end{array}$ \\
\hline & $\mathrm{HF}$ & 31 & $\begin{array}{c}4.03 \\
(3.64-4.47)\end{array}$ & 31 & $\begin{array}{c}3.39 \\
(2.61-4.42)\end{array}$ & 30 & $\begin{array}{c}3.10 \\
(2.35-4.09)\end{array}$ & 28 & $\begin{array}{c}2.64 \\
(2.04-3.42)\end{array}$ \\
\hline
\end{tabular}

Values shown are unadjusted means $\pm \mathrm{SD}$ or geometric means $(95 \% \mathrm{CI})$ 


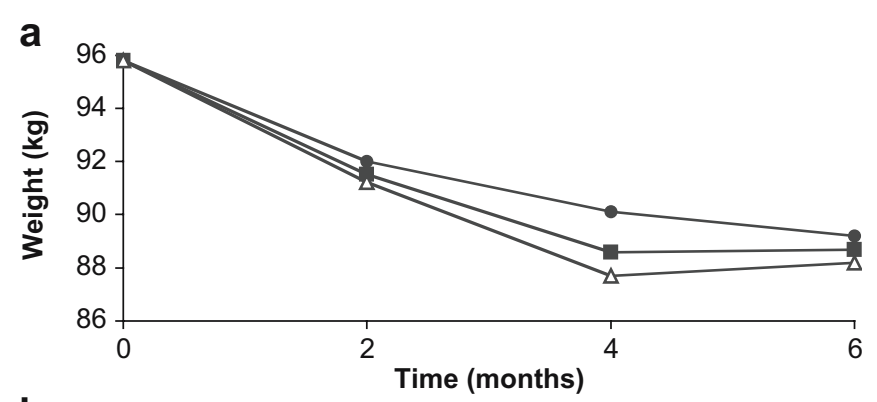

b

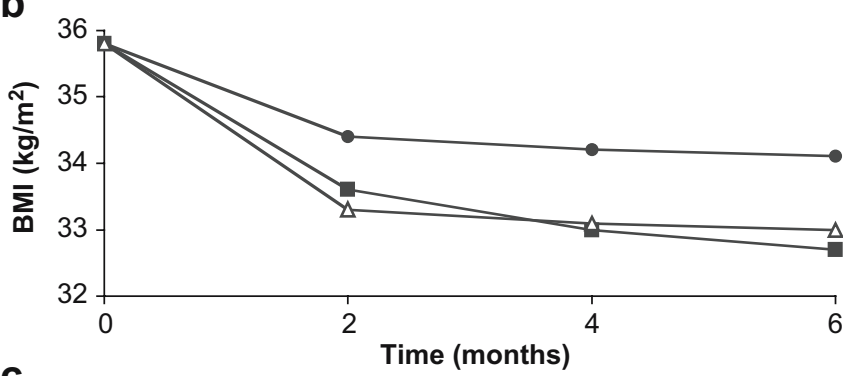

C

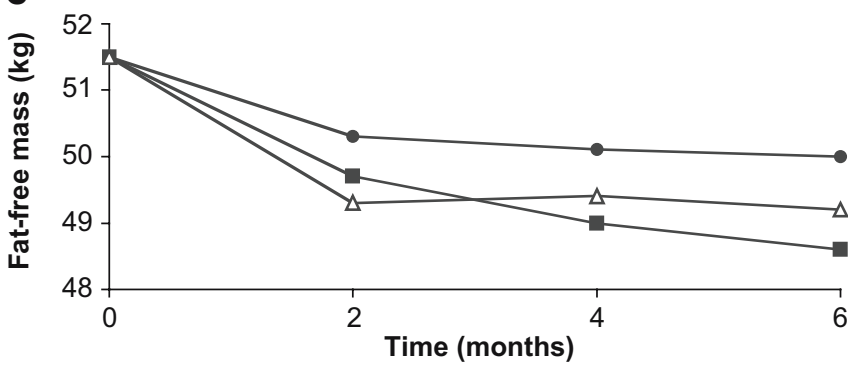

Fig. 2 Mean weight (a), BMI (b), and fat-free mass (c) of the three dietary groups at each time point adjusted for baseline values. Unadjusted mean values are given in Table 3. Circles HC diet, squares HP diet, triangles HF diet

$p=0.03$ ). Fasting triglycerides, although reduced by all three diets, fell to a significantly greater extent with the HP and $\mathrm{HF}$ diets than with the $\mathrm{HC}$ diet. Overall, LDL cholesterol was lower in the HP group than in the $\mathrm{HC}$ group. Levels of LDL cholesterol were increased by $>10 \%$ in eight individuals $(25 \%)$ in the HF group, four $(13 \%)$ in the HC group and one $(3 \%)$ in the HP group. Weight showed a significant time interaction. When compared with the $\mathrm{HC}$ group, body weight and BMI were reduced to a greater extent in the HF group than in the HP group at week 8. At week 16 the HF and HP groups showed similar reductions in these two parameters, whereas by week 24 the HP group showed greater reductions than the HF group.

No significant differences were observed between the dietary groups with respect to systolic blood pressure, fasting and 2-h glucose, fasting insulin and CRP.

\section{Discussion}

This study is the first to compare two popular weightreducing diets $[7,8]$ with the high-carbohydrate, high-fibre approach [5] in women at high risk of type 2 diabetes and cardiovascular disease. The high overall retention rate $(88 \%)$ over a 6-month period allowed us to perform an intention-to-treat analysis. This has not been possible in many of the earlier controlled comparisons due to much higher dropout rates [9-11]. A further strength of this study is that it permits the assessment of the diets as they would operate in the real world, where total compliance with a dietary prescription is difficult to achieve.

All three diets produced weight loss to an extent which might be expected to reduce the risk of type 2 diabetes [4] and cardiovascular disease [17]. Compared with the HC diet, the HF and HP diets produced greater reductions in weight. Although subjects on the two alternative diets lost a similar amount of weight, the initial weight loss appeared greater in the HF group, whereas later in the study the difference was reversed. This may be explained by the early fluid loss that occurs on a low-carbohydrate diet [18]. Other studies comparing a single popular diet with the conventional approach have also reported that greater weight loss is achieved with HF and HP diets than with $\mathrm{HC}$ diets $[9,10,19-23]$, and there is much speculation regarding the mechanisms responsible for these findings [19]. The majority of earlier studies in which macronutrient composition was altered against a background of constant energy intake reported no difference in weight change when HP [24-26] or HF diets [27] were compared with $\mathrm{HC}$ diets. Only when the diets were consumed ad libitum was a difference in weight loss apparent $[9,10,23]$. Although energy intake seemed to be restricted to a similar extent by all three diets in the present study, the results suggest that under-reporting took place. Threeday diet records are not sensitive enough to detect small differences in energy intakes (of approximately $500 \mathrm{~kJ} /$ day) which, over a period of months, could account for the observed differences in weight loss (about $3 \mathrm{~kg}$ ) between the groups. It seems likely that greater weight losses observed when HF or HP alternatives are compared with $\mathrm{HC}$ diets (consumed without energy prescription) are the result of reduced energy consumption rather than the use of alternative fuel sources due to the altered macronutrient composition of the diets. Reduced energy intake on such diets may result from the novelty of a new diet, monotony due to restriction of accessible foods, or enhanced satiety or a reduced appetite due to the ketonuria that is associated with carbohydrate restriction.

Concern has been expressed regarding the long-term safety of HF diets, particularly the potential for such diets to elevate total and LDL cholesterol [28]. In this study, the observed increases in these parameters were less than expected, probably due to the concomitant reduction in energy intake and weight loss. Although LDL levels were not markedly increased by the HF diet, levels were significantly higher in the HF group than in the HP group, despite the fact that the two groups lost a similar amount of weight. Furthermore, the HF regimen produced a marked increase in LDL cholesterol in a small number of participants, suggesting that some individuals may be particularly sensitive to substantial increases in fat intake [29]. 
Table 4 Mean differences between the dietary interventions after adjusting for baseline values

Data at weeks 8,16 and 24 have been combined. The overall test based on the chi-square distribution was statistically significant for all variables presented ${ }^{a}$ This variable showed a significant time interaction, as illustrated in Fig. 2. HC $n=32$, HP $n=30$, HF $n=31$ (missing values are explained in the text)

\begin{tabular}{|c|c|c|c|c|}
\hline & Diet group & Difference between diets & $95 \% \mathrm{CI}$ & $p$ value \\
\hline \multirow[t]{3}{*}{ Weight $^{\mathrm{a}}(\mathrm{kg})$} & $\mathrm{HP}-\mathrm{HC}$ & -2.71 & -4.52 to -0.90 & 0.003 \\
\hline & $\mathrm{HF}-\mathrm{HC}$ & -2.82 & -4.60 to -1.04 & 0.002 \\
\hline & HF-HP & -0.11 & -1.92 to 1.70 & 0.91 \\
\hline \multirow[t]{3}{*}{$\operatorname{BMI}^{\mathrm{a}}\left(\mathrm{kg} / \mathrm{m}^{2}\right)$} & HP-HC & -1.13 & -1.81 to -0.45 & 0.001 \\
\hline & $\mathrm{HF}-\mathrm{HC}$ & -1.10 & -1.76 to -0.43 & 0.001 \\
\hline & HF-HP & 0.03 & -0.65 to 0.72 & 0.92 \\
\hline \multirow[t]{3}{*}{ Waist (cm) } & HP-HC & -2.66 & -5.33 to 0.00 & 0.05 \\
\hline & $\mathrm{HF}-\mathrm{HC}$ & -3.48 & -6.13 to -0.84 & 0.010 \\
\hline & HF-HP & -0.82 & -3.51 to 1.87 & 0.55 \\
\hline \multirow[t]{3}{*}{ Fat-free mass ${ }^{\mathrm{a}}(\mathrm{kg})$} & HP-HC & -1.00 & -1.85 to -0.16 & 0.020 \\
\hline & $\mathrm{HF}-\mathrm{HC}$ & -0.84 & -1.67 to 0.00 & 0.049 \\
\hline & HF-HP & 0.17 & $-0: 68$ to 1.01 & 0.70 \\
\hline \multirow[t]{3}{*}{ Fat mass (kg) } & HP-HC & -1.64 & -3.03 to -0.25 & 0.021 \\
\hline & $\mathrm{HF}-\mathrm{HC}$ & -1.76 & -3.13 to -0.39 & 0.012 \\
\hline & HF-HP & -0.12 & -1.51 to 1.27 & 0.86 \\
\hline \multirow[t]{3}{*}{ Total cholesterol (mmol/1) } & HP-HC & -0.14 & -0.39 to 0.12 & 0.30 \\
\hline & $\mathrm{HF}-\mathrm{HC}$ & 0.19 & -0.06 to 0.45 & 0.14 \\
\hline & HF-HP & 0.33 & 0.07 to 0.59 & 0.01 \\
\hline \multirow[t]{3}{*}{ HDL cholesterol (mmol/1) } & $\mathrm{HP}-\mathrm{HC}$ & 0.03 & -0.05 to 0.11 & 0.47 \\
\hline & HF-HC & 0.11 & 0.02 to 0.19 & 0.011 \\
\hline & HF-HP & 0.08 & -0.01 to 0.16 & 0.07 \\
\hline \multirow[t]{3}{*}{ LDL cholesterol (mmol/1) } & $\mathrm{HP}-\mathrm{HC}$ & -0.09 & -0.34 to 0.15 & 0.45 \\
\hline & $\mathrm{HF}-\mathrm{HC}$ & 0.19 & -0.04 to 0.43 & 0.11 \\
\hline & HF-HP & 0.28 & 0.04 to 0.52 & 0.02 \\
\hline \multirow[t]{3}{*}{ Triglycerides (mmol/1) } & $\mathrm{HP}-\mathrm{HC}$ & -0.22 & -0.40 to -0.04 & 0.02 \\
\hline & HF-HC & -0.30 & -0.48 to -0.12 & 0.00 \\
\hline & HF-HP & -0.08 & -0.26 to 0.10 & 0.41 \\
\hline
\end{tabular}

Fasting triglycerides were reduced by all three diets, but more so by the two popular diets. Fasting triglycerides decrease with weight loss, and carbohydrate-reduced diets have been reported to produce greater reductions than $\mathrm{HC}$ diets. The results of energy-controlled studies [24, 27] suggest that carbohydrate restriction may in itself result in lower triglyceride levels; however, these studies were of short duration, and did not allow for adaptation to a $\mathrm{HC}$ diet. Furthermore, only when $\mathrm{HC}$ diets are derived from intact vegetables and fruit and wholegrain cereals is the full potential benefit observed in terms of lipid profile and glycaemic control [30]. In the present study, participants on the HC diet achieved only a modest increase in fibre density, and thus did not receive the maximum benefit of such a dietary regimen. In accordance with a previous study [9], the HF diet produced a small increase in HDL cholesterol which was similar to that observed for the HP diet, but greater than that produced by the HC diet.

During the first 8 weeks of the study all three diets produced a decrease in fasting insulin levels that was maintained throughout the study period. The observed improvement in key indicators of insulin resistance (central adiposity, hyperinsulinaemia and hypertriglyceridaemia) confirms that insulin sensitivity was improved by all three dietary regimens. The greater reductions in waist circumference and triglycerides observed in the HF and HP groups indicate that insulin sensitivity may have been improved to a greater extent by the alternative diets than by the $\mathrm{HC}$ diet. However, given that the aim in insulinresistant individuals is to reduce the cardiovascular risk as well as to reduce the risk of developing diabetes, the observed effect of the HF approach on LDL levels suggests that the HP diet offers a distinct advantage. Furthermore, a HF diet has been linked to other potentially deleterious effects not measured in the present study, including increased risk of thrombosis and cardiovascular disease associated with insufficient intake of wholegrain cereals [31]. Our data does not indicate that any of the observed benefits afforded by the HF and HP diets are a consequence of macronutrient composition; rather, they seem more likely to be secondary to the greater weight loss produced by these diets.

The beneficial effects of the HP diet were achieved without full compliance. Protein and carbohydrate intakes in the HP group were lower than intended, and fat intake was rather higher. Many participants did not achieve the required meal frequency. Thus, it would seem that the most frequent criticism of the Zone Diet-its rigid adherence to meal timing, is not an essential prerequisite to successful implementation.

Those on the HC diet did not meet the targets for carbohydrate and fibre intakes, and saturated fatty acid intake remained higher than intended. Indeed, subjects in the HP group were as close to achieving the $\mathrm{HC}$ targets for fibre intake as those in the $\mathrm{HC}$ group were. Given the high level of motivation of the volunteers, it seems likely that the 
guidelines employed to implement the $\mathrm{HC}$ recommendations were insufficiently specific. It is probably necessary to be more directional with regard to fruit, vegetables and wholegrain cereals, which must be consumed in order to achieve targets [30]. A diet that achieves the target carbohydrate and fibre levels (by increasing quantities of wholegrains, intact vegetables and fruits) would probably provide a benefit similar to that afforded by the HP approach.

In conclusion, the HF Atkins Diet is a successful shortterm approach for weight loss; however, LDL levels should be monitored, and those who show a significant increase should be advised to discontinue the diet. The potential deleterious effects of the diet in the long-term remain a concern. In the context of this study the HP Zone Diet appears to be the most appropriate overall approach to reducing the risk of cardiovascular disease and type 2 diabetes.

Acknowledgements We would like to thank all of the participants: G. Henshaw, who was the study dietitian; M. Harper and A. Duncan, who undertook most of the laboratory analyses; and R. Brown who provided technical assistance. We would like to thank the Health Research Council of New Zealand for funding this project. The authors are not aware of any conflict of interest in this study.

\section{References}

1. Tuomilehto J, Lindstrom J, Eriksson J et al (2001) Prevention of type 2 diabetes mellitus by changes in lifestyle among subjects with impaired glucose tolerance. $\mathrm{N}$ Engl J Med 344:1343-1350

2. Group Diabetes Prevention Program Research (2002) Reduction in the incidence of type 2 diabetes with lifestyle intervention or metformin. N Engl J Med 346:393-403

3. McAuley KA, Williams SM, Mann JI et al (2002) Intensive lifestyle changes are necessary to improve insulin sensitivitya randomised controlled trial. Diabetes Care 25:445-452

4. American Diabetes Association (2003) Evidence-based nutrition principles and recommendations for the treatment and prevention of diabetes and related complications. Diabetes Care 26 [Suppl 1]:S51-S61

5. Diabetes and Nutrition Study Group (DNSG) of the European Association for the Study of Diabetes (EASD) (2000) Recommendations for the nutritional management of patients with diabetes mellitus. Eur J Clin Nutr 54:353-355

6. Krauss RM, Eckel RH, Howard B et al (2000) AHA Dietary Guidelines. Revision 2000: a statement for healthcare professionals from the nutrition committee of the American Heart Association. Circulation 102:2284-2299

7. Atkins RC (1992) Dr Atkins' new diet revolution. Avon Books, New York

8. Sears B (2000) A week in the Zone. 1st edn. Harper Collins, New York

9. Foster GD, Wyatt HR, Hill JO et al (2003) A randomized trial of a low-carbohydrate diet for obesity. $N$ Engl J Med 348:2082-2090

10. Samaha FF, Iqbal N, Seshadri P et al (2003) A lowcarbohydrate as compared with a low-fat diet in severe obesity. N Engl J Med 348:2074-2081

11. Landers P, Wolfe M, Glore S, Guild R, Phillips L (2002) Effect of weight loss plans on body composition and diet duration. $\mathrm{J}$ Okla State Med Assoc 95:329-331
12. Alberti KG, Zimmet PZ (1998) Definition, diagnosis and classification of diabetes mellitus and its complications. Part 1: diagnosis and classification of diabetes mellitus provisional report of a WHO consultation. Diabet Med 15:539-553

13. McAuley KA, Williams SM, Mann JI et al (2001) Diagnosing insulin resistance in the general population. Diabetes Care 24:460-464

14. New Zealand Ministry of Health (2003) Food and nutrition guidelines for healthy adults: a background paper. Ministry of Health, Wellington, NZ

15. National Institutes of Health (1996) Bioelectrical impedance analysis in body composition measurement: National Institutes of Health Technology Assessment Conference Statement. Am J Clin Nutr 64(Suppl 3):524S-532S

16. Vickers AJ, Altman DG (2001) Analysing controlled trials with baseline and follow up measurements. Br Med J 323:11231124

17. Williamson DF, Pamuk E, Thun M, Flanders D, Byers T, Heath C (1995) Prospective study of intentional weight loss and mortality in never-smoking overweight US white women aged 40-64 years. Am J Epidemiol 141:1128-1141

18. Yang MU, Van Itallie TB (1976) Composition of weight lost during short-term weight reduction. Metabolic responses of obese subjects to starvation and low-calorie ketogenic and nonketogenic diets. J Clin Invest 58:722-730

19. Brehm BJ, Seeley RJ, Daniels SR, D'Alessio DA (2003) A randomized trial comparing a very low carbohydrate diet and a calorie-restricted low fat diet on body weight and cardiovascular risk factors in healthy women. J Clin Endocrinol Metab 88:1617-1623

20. Baba NH, Sawaya S, Torbay N, Habbal Z, Azar S, Hashim SA (1999) High protein vs high carbohydrate hypoenergetic diet for the treatment of obese hyperinsulinemic subjects. Int J Obes 23:1202-1206

21. Baron JA, Schori A, Crow B, Carter R, Mann JI (1986) A randomized controlled trial of low carbohydrate and low fat/ high fiber diets for weight loss. Am J Public Health 76:12931296

22. Parker B, Noakes M, Luscombe N, Clifton P (2002) Effect of a high-protein, high-monounsaturated fat weight loss diet on glycemic control and lipid levels in type 2 diabetes. Diabetes Care 25:425-430

23. Skov AR, Toubro S, Ronn B, Holm L, Astrup A (1999) Randomized trial on protein vs carbohydrate in ad libitum fat reduced diet for the treatment of obesity. Int J Obes 23:528-536

24. Lean ME, Han TS, Prvan T, Richmond PR, Avenell A (1997) Weight loss with high and low carbohydrate $1200 \mathrm{kcal}$ diets in free living women. Eur J Clin Nutr 51:243-248

25. Luscombe ND, Clifton PM, Noakes M, Parker B, Wittert G (2002) Effects of energy-restricted diets containing increased protein on weight loss, resting energy expenditure, and the thermic effect of feeding in type 2 diabetes. Diabetes Care 25:652-657

26. Farnsworth E, Luscombe ND, Noakes M, Wittert G, Argyiou E, Clifton PM (2003) Effect of a high-protein, energy-restricted diet on body composition, glycemic control, and lipid concentrations in overweight and obese hyperinsulinemic men and women. Am J Clin Nutr 78:31-39

27. Golay A, Allaz AF, Morel Y, de Tonnac N, Tankova S, Reaven G (1996) Similar weight loss with low- or high-carbohydrate diets. Am J Clin Nutr 63:174-178

28. Law M (2000) Dietary fat and adult diseases and the implications for childhood nutrition: an epidemiological approach. Am J Clin Nutr 72:1291S-1296S

29. Schaefer EJ, Laman-Fava S, Ausman LM et al (1997) Individual variability in lipoprotein cholesterol response to National Cholesterol Education Programme Step 2 diets. Am J Clin Nutr 65:823-830

30. Mann J (2001) Dietary fibre and diabetes revisited, Editorial. Eur J Clin Nutr 55:919-921

31. Anderson JW (2003) Wholegrains protect against atherosclerotic cardiovascular disease. Proc Nutr Soc 62:135-142 